\title{
Behavior of Normal Pulmonary Circulation during Changes of Total Blood Volume in Man*
}

\author{
Flavio M. de Freitas, $\dagger$ Eduardo Z. Faraco, Decio F. de Azevedo, Jaime \\ Zaduchliver, and IsaAC Lewin \\ (From the Cardio-pulmonary Laboratory, Department of Clinical Therapeutics, Pôrto Alegre \\ Medical School, University of Rio Grande do Sul, Pôrto Alegre, Rio Grande do Sul, Brazil)
}

It has been demonstrated by many authors, both in patients with heart disease and in normal subjects, that the pulmonary arterial and venous pressures can be raised or lowered by increasing or decreasing the total blood volume (1-6). These pressure alterations are generally thought to occur in association with changes of the pulmonary blood volume, which is believed to increase or decrease simultaneously with a rise or fall in total circulating volume $(1-3,7,8)$. However, in the majority of reports published on this subject, the pulmonary blood volume was either not measured $(1,5,6)$ or estimated from "central" blood volume determinations $(2,3,7)$, which are known to encompass many drawbacks and pitfalls $(9,10)$. More recently, Oakley and associates (11) studied four patients with rheumatic heart disease during the intravenous administration of dextran or saline solutions and found an increase of the pulmonary blood volume measured by the method of Milnor, Jose, and McGaff (12).

Another aspect requiring evaluation is the behavior of the pulmonary vascular resistance. In the pulmonary circulation of open-chested anesthetized dogs, the vascular resistance has been shown to vary inversely with the vascular distending (transmural) pressure when the mechanical effect predominates (13). In these experiments the pulmonary arterial and left atrial pressures were raised or lowered by the rapid infusion or withdrawal of relatively large volumes of blood (13). No human counterpart of such findings is available in the literature, since data on the pulmonary vascular resistance obtained during similar studies

\footnotetext{
* Submitted for publication July 29, 1964; accepted November 12, 1964.

$\dagger$ Address requests for reprints to: Dr. Flavio M. de Freitas, Cátedra de Terapêutica Clinica, Faculdade de Medicina de Pôrto Alegre, Universidade do Rio Grande do Sul, Pôrto Alegre, R. G. S., Brazil.
}

carried out in intact man are scarce and inconsistent $(2-4,11)$.

The present investigation was therefore designed to ascertain whether the pressure alterations induced in normal pulmonary circulation, during changes in total volemia, are accompanied by variations of the vascular resistance and of the pulmonary blood volume. For this purpose patients were submitted to right- and left-heart catheterization while total "effective" blood volume was varied by the rapid infusion of a plasma expander or by peripheral venous blood pooling.

\section{Methods}

Twenty-six male patients aged 16 to 46 years (average, 30 years) were studied. Fifteen of them had no detectable cardiovascular abnormalities and were suffering from illnesses that had not impaired importantly their general physical conditions and were unrelated to the circulatory system. In this group, the principal diagnosis was helminthiasis in nine cases, peptic ulcer in three, hiatal hernia in two, and simple goiter in one case. Six patients underwent cardiac catheterization because of systolic murmurs that were found to be functional, since no hemodynamic alterations could be demonstrated. The remaining five had systemic arterial hypertension, with no signs of cardiac or renal failure, and were not receiving antihypertensive drugs. Although all patients had been hospitalized from 1 to 20 days before the study, none of them was confined to complete bed rest. A full explanation of the nature and aim of the procedure was made to all patients who gave their consent for the studies to be carried out.

Thirty minutes before the beginning of the experiment, each patient received orally $100 \mathrm{mg}$ of secobarbital and $50 \mathrm{mg}$ of butabarbital. A 7F $125-\mathrm{cm}$, Teflon catheter (USCI T-52) was introduced through the left antecubital vein and advanced into the pulmonary artery to a point just distal to the pulmonic valve. In some cases, another catheter $(6 \mathrm{~F}, 100-\mathrm{cm})$ was also introduced through the same vein and placed in the right atrium for the continuous recording of pressure in this cavity. A $70-\mathrm{cm}$ Teflon catheter (USCI BR-70) was used for left-heart catheterization, which was performed via the right fe- 
moral vein, in accordance with the modification of the Ross transeptal technic described by Brockenbrough and Braunwald (14). The tip of the left-heart catheter was just proximal to the mitral valve. For the injection of the indicator dye, an Ödman-Ledin $40-\mathrm{cm}$ polyethylene radiopaque catheter (Kifa, yellow) was introduced percutaneously (15), through the left femoral vein, into the inferior vena cava, and located about $10 \mathrm{~cm}$ below the entrance of the right atrium. A Cournand needle was inserted in the femoral artery.

Pressures were measured with Statham P23Db transducers. Electronically integrated mean pressures were recorded during at least three respiratory cycles. Dye dilution curves were obtained from blood sampled simultaneously from the pulmonary artery and left atrium through two cuvette densitometers ${ }^{1}$ of similar characteristics. Pressures and dye curves were recorded on a cathode-ray photographic system. ${ }^{2}$

The technic for the determination of the pulmonary blood volume was described in detail elsewhere (16). Cardio-green dye ${ }^{3}$ (1.0 to $\left.1.5 \mathrm{ml}\right)$ was rapidly injected ( 0.5 second or less) into the inferior vena cava, and blood was sampled through the catheters placed in the pulmonary artery and left atrium by the use of two identical syringes that were driven by the same motor at a constant speed (flow rate, $0.6 \mathrm{ml}$ per second). Sterilization of the sampling system allowed all the blood withdrawn for dye curves to be returned to the patient. Cardiac output and mean transit time were calculated as proposed by Hamilton, Moore, Kinsman, and Spurling (17). The volumetric technic of Lenkei, Fox, and Lynn (18) was used for calibration of the curves. For this purpose, blood samples were obtained before and after each complete study. Appropriate dilutions were made by adding known amounts of dye to $25-\mathrm{ml}$ samples of blood. At equal dye concentrations, deflections obtained with the blood sample at the end of the determinations on each subject were not consistently different from those obtained on the blood sample taken before the corresponding study. During the calibration process, blank and standard dilution samples were passed through both densitometer cuvettes, which were connected in series. The volume, in milliliters, from the tip of each catheter to the middle of each cuvette, was accurately measured and divided by the rate of sampling flow, in milliliters per second, for the calculation of the delay in the collecting system. Calculated delays varied from 2.7 to 2.9 seconds and were subtracted from the respective mean transit time measurements. The volume of circulating blood between the site of injection and the sites of sampling (all temporally equidistant points included) was computed as follows: IVC-PA $\mathrm{BV}=$ IVC-PA $\mathrm{MTT} \times \mathrm{CO}$, IVC-LA $\mathrm{BV}=$ IVC-LA MTT $\times$ CO, and PA-LA BV or PBV $=($ IVCLA MTT - IVC-PA MTT) $\times$ CO, where IVC-PA BV and IVC-LA BV are the blood volumes, in milliliters, between the inferior vena cava and pulmonary artery, and

1 X-250, Waters Corp., Rochester, Minn.

2 Electronics for Medicine, White Plains, N. Y.

3 Hynson, Westcott, and Dunning, Baltimore, Md. between the inferior vena cava and left atrium, respectively. MTT is the mean transit time, in seconds, and $\mathrm{CO}$ is the average cardiac output, in milliliters per second, as calculated from the two curves recorded simultaneously. PA-LA BV is the volume of blood, in milliliters, between the pulmonary artery and left atrium, or the pulmonary blood volume (PBV). Results were referred to body surface area (BSA) in square meters. As was pointed out in a previous paper (16), the pulmonary blood volume measured by this technic includes, almost certainly, the major portion of or the entire left atrial volume. In a series of duplicate or triplicate determinations of the pulmonary blood volume carried out in 24 patients by this method, the average percentile variation of the results around the mean values was equal to $3.2 \pm 2.7 \mathrm{SD}$ (16). The IVC-PA blood volume, depending on the position of the catheter for dye injection, includes variable portions of the inferior and superior venae cavae and their tributaries, as well as the right atrium and ventricle. Therefore the IVC-PA designation connotes only the sites of injection and sampling used for the determination of a volume of blood, the physical limits of which, in the systemic venous vasculature, cannot be precisely indicated.

After the catheters were in place, pressures from the pulmonary and femoral arteries and from right and left atria were recorded simultaneously. Immediately afterwards, dye was injected into the inferior vena cava for the determination of the cardiac output and of the IVCPA and pulmonary blood volumes. These measurements were considered as control and were obtained in duplicate. Blood volume was increased by infusing through the catheter in the pulmonary artery a balanced multielectrolyte solution containing $3.5 \%$ polyvinylpyrrolidone. ${ }^{4}$ The solution is isotonic and isoviscous in relation to blood plasma (19) and was warmed to body temperature before injection. Infusion was accomplished by a motor-driven syringe at a constant rate of $38 \mathrm{ml}$ per minute. Infusion was interrupted during an average period of 5 minutes, after 300 to $400 \mathrm{ml}, 600$ to $700 \mathrm{ml}$, and $1,000 \mathrm{ml}$ had been administered, for new recording of data. Peripheral venous blood pooling was achieved by the inflation of rubber cuffs placed on both arms and both thighs to a pressure level about $10 \mathrm{~mm} \mathrm{Hg}$ below the diastolic systemic arterial pressure. Cuffs were kept inflated during a period varying from 10 to 15 minutes. After at least 5 minutes of cuff inflation, the same measurements made during the control period were repeated. Either after the infusion of polyvinylpyrrolidone or during peripheral venous blood pooling, data were obtained in duplicate. When an additional catheter for the recording of pressure from the right atrium was not used, pressure in this cavity was recorded initially, before the right-heart catheter was introduced into the pulmonary artery, and again during the withdrawal of the catheter at the end of the experiment, after the plasma expander infusion had been completed or while the cuffs were inflated.

4 Subtosan, kindly supplied by Companhia Química Rhodia Brasileira, São Paulo, Brazil. 


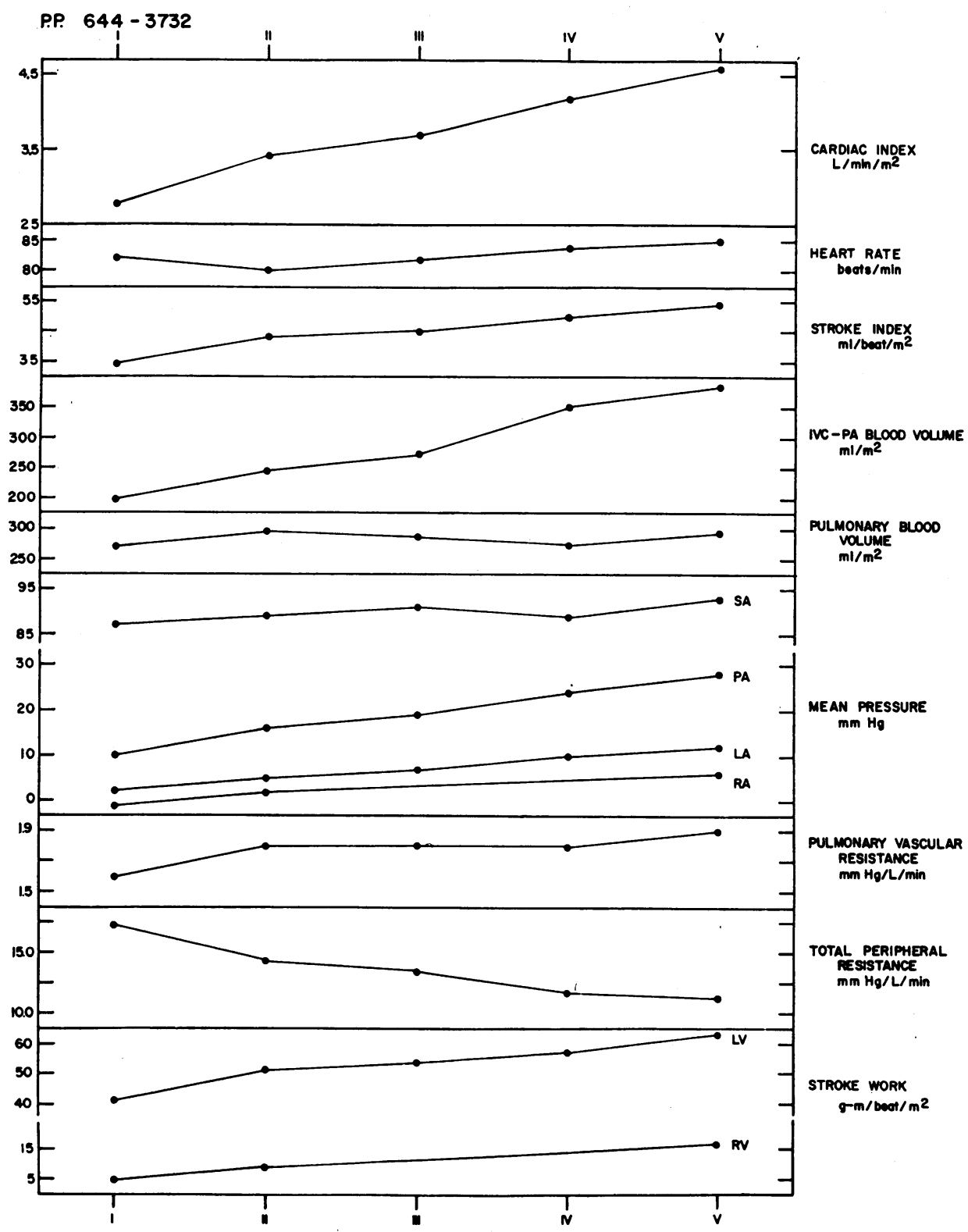

Fig. 1. Hemodynamic changes during peripheral venous blood pooling and polyVINYLPYRROLIDONE INFUSION IN A REPRESENTATIVE CASE. Periods of study are as follows: I, peripheral venous blood pooling; II, control; III, IV, and V, after $350 \mathrm{ml}, 700 \mathrm{ml}$, and 1,000 $\mathrm{ml}$ of polyvinylpyrrolidone infusion, respectively. Abbreviations: SA, systemic artery; PA, pulmonary artery; LA, left atrium; RA, right atrium; LV, left ventricle; RV, right ventricle; IVC, inferior vena cava.

Twelve patients were subjected only to polyvinylpyrrolidone infusion. In seven others, observations were limited to the effects of peripheral venous blood pooling. In the remaining seven, the hemodynamic effects of both procedures used to change the total "effective" blood volume were observed in each case, peripheral venous blood pooling being carried out before or after the infusion of the solution containing polyvinylpyrrolidone.

The pulmonary vascular resistance (PVR), total peripheral resistance (TPR), and the average intravascular pressure (AIP) in the pulmonary circulation were calculated as follows: $\mathrm{PVR}=(\mathrm{MPAP}-\mathrm{MLAP}) /$ 
$\mathrm{CO}, \mathrm{TPR}=\mathrm{MSAP} / \mathrm{CO}$, and AIP $=(\mathrm{MPAP}+\mathrm{MLAP})$ /2. In these formulae, MPAP, MLAP, and MSAP are the mean pulmonary arterial, mean left atrial, and mean systemic arterial pressures in millimeters $\mathrm{Hg}$, respectively. $\mathrm{CO}$ is the cardiac output in liters per minute. The results for resistance are expressed in millimeters $\mathrm{Hg}$ per liter per minute. The changes in average intravascular pressure were used, as an approximation, to estimate changes in transmural pressure in the pulmonary vessels $(13,16,20)$.

The stroke work of the left ventricle (LVSW) and of the right ventricle (RVSW) was calculated in grammeters per beat per square meter of BSA, by the formulae $:$ LVSW $=[($ MSAP - MLAP $) \times$ SI $\times 1.055] / 100$ and $\mathrm{RVSW}=[(\mathrm{MPAP}-\mathrm{MRAP}) \times \mathrm{SI} \times 1.055] / 100$, in which MSAP, MLAP, MPAP, and MRAP are the mean systemic arterial, mean left atrial, mean pulmonary arterial, and mean right atrial pressures in centimeters $\mathrm{H}_{2} \mathrm{O}$, respectively. SI is the stroke index in milliliters per beat per square meter of BSA.

\section{Results}

The mean control values and the average results obtained after polyvinylpyrrolidone infusion and peripheral venous blood pooling are listed in Tables I and II. The hemodynamic changes that occurred in a representative case are also displayed in Figure 1.

Effect of polyvinylpyrrolidone infusion (Table $I$ ). The cardiac output increased in all patients, and the stroke volume increased in all but one after the administration of the plasma expander. The increase was already noted when 300 to 400 $\mathrm{ml}$ had been injected and rose steadily until the infusion was completed. Average changes after the administration of $1,000 \mathrm{ml}$ were $+28 \%$ (range, +11 to $+52 \%$ ) for the cardiac output and $+19 \%$ (range, 0 to $+45 \%$ ) for the stroke volume. At the same time, the heart rate rose in 14 patients, fell in two, and did not change in one, with an average change of $+8 \%$ (range, -3 to $+21 \%$ ).

A simultaneous and significant increase was observed in the pulmonary arterial and venous (left atrial) pressures. Changes were, on an average, $+88 \%$ (range, +40 to $+186 \%$ ) for the mean pulmonary arterial pressure and $+161 \%$ (range, +13 to $+275 \%$ ) for the mean left atrial pressure.

In 11 of the 17 patients in whom an infusion of $1,000 \mathrm{ml}$ was completed, there was a rise in pulmonary vascular resistance. A fall was observed in four patients, and no change occurred in two. The average change was $+17 \%$, within a total range of -17 to $+150 \%$. In 12 patients, however, variations were between -10 and $+10 \%$. These results were found to be not significant.

The pulmonary blood volume increased in ten patients and decreased in seven. Variations ranged from -17 to $+30 \%$, but did not exceed $\pm 10 \%$ in 14 patients. The average change was $+3 \%$.

The mean systemic arterial pressure increased slightly in 15 patients. In the remaining two patients, there was a decrease in one and no alteration in the other. Changes averaged $+7 \%$ in relation to control data, with a range of -9 to $+24 \%$.

A rise of the mean right atrial pressure was observed in all patients, with an average change of $+207 \%$ and a range of +80 to $+400 \%$.

The fall in total peripheral resistance averaged $-16 \%$ within the -36 to $-1 \%$ range.

The IVC-PA blood volume increased in 15 patients and decreased in two. The average change observed was $+24 \%$, with a range of -6 to $+60 \%$.

Right ventricular stroke work and left ventricular stroke work increased in all, and in 15 patients, respectively. In two patients, a slight fall in the stroke work of the left ventricle was observed. The average changes in stroke work were $+97 \%$ (range, +22 to $+333 \%$ ) for the right ventricle, and $+18 \%$ (range, -7 to $+42 \%$ ) for the left ventricle.

During the control period, hematocrit readings in ten patients averaged $42.3 \pm 0.9 \mathrm{SE}$. These mean figures changed to $37.6 \pm 0.8 \mathrm{SE}$ after the administration of $1,000 \mathrm{ml}$ of polyvinylpyrrolidone solution.

Effects of peripheral venous blood pooling ( $T a$ ble II). In general the hemodynamic changes that occurred during the application of tourniquets on the limbs were opposite in direction to those found after polyvinylpyrrolidone infusion.

A fall in cardiac output was noted in all patients. Changes ranged from -26 to $-2 \%$ and averaged $-16 \%$. A simultaneous decrease occurred in stroke volume, except in one patient. The average change was $-17 \%$ with a range of -24 to $0 \%$. The heart rate increased in eight patients, decreased in four, and remained unaltered in two. Most of the changes were of low magnitude, with an average of $+4 \%$ and a range of -3 to $+19 \%$. 


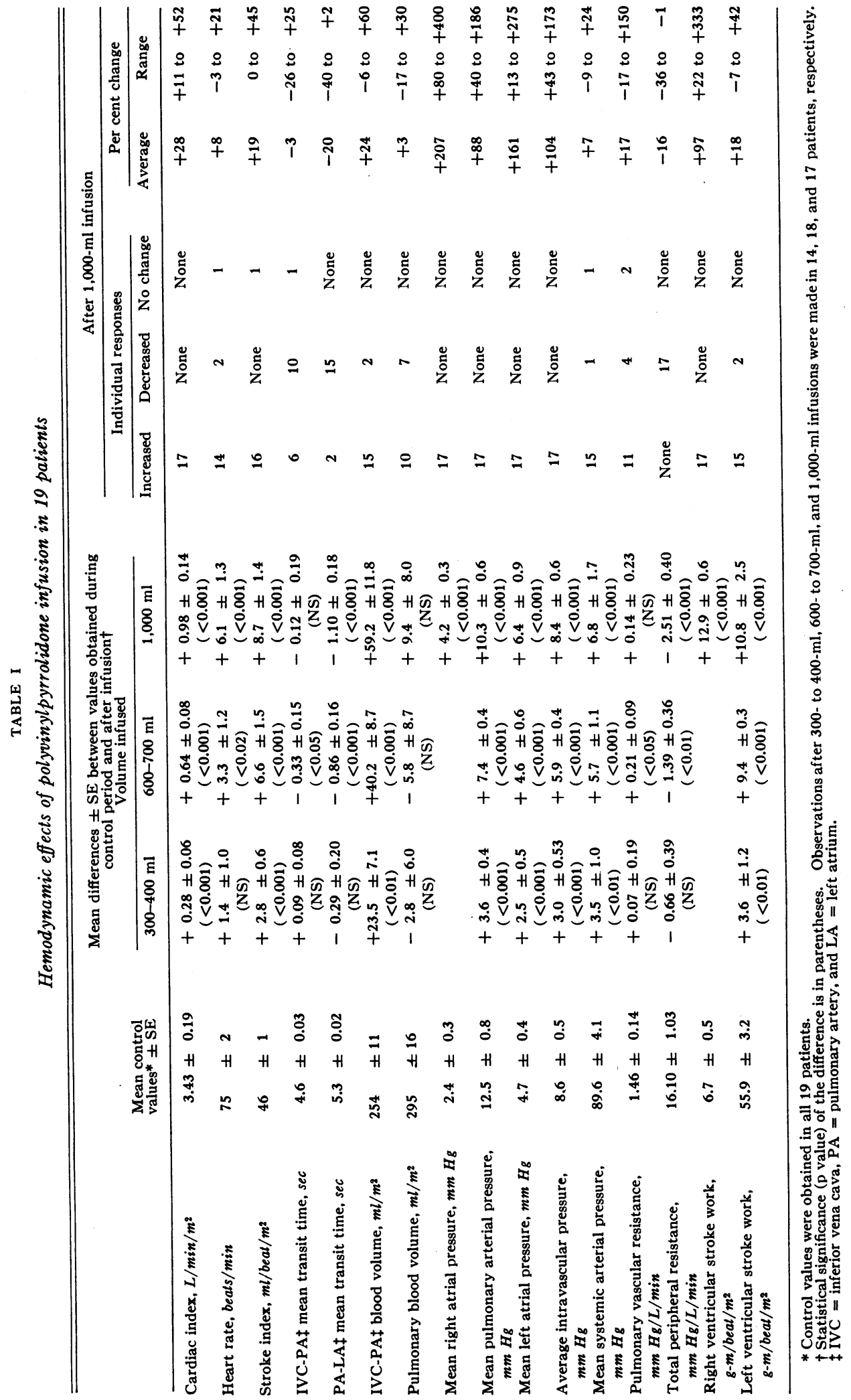


TABLE II

Hemodynamic effects of peripheral venous blood pooling in 14 patients

\begin{tabular}{|c|c|c|c|c|c|c|c|c|}
\hline & \multirow{2}{*}{\multicolumn{2}{|c|}{$\begin{array}{l}\text { Mean control } \\
\text { values } \pm S E\end{array}$}} & \multirow{3}{*}{$\begin{array}{c}\begin{array}{c}\text { Mean differences } \\
\pm \text { SE between } \\
\text { values obtained } \\
\text { during control } \\
\text { period and dur- } \\
\text { ing peripheral } \\
\text { venous blood } \\
\text { pooling* }\end{array} \\
-\begin{array}{l}0.55 \pm 0.06 \\
(<0.001)\end{array}\end{array}$} & \multicolumn{3}{|c|}{ Individual responses } & \multicolumn{2}{|c|}{ Per cent change } \\
\hline & & & & Increased & $\begin{array}{l}\text { De- } \\
\text { creased }\end{array}$ & No change & Average & Range \\
\hline Cardiac index, $L / m i n / m^{2}$ & 3.36 & $6 \pm 0.21$ & & None & 14 & None & -16 & -26 to -2 \\
\hline Heart rate, beats/min & 78 & \pm 2 & $\begin{array}{c}+3.3 \pm 1.6 \\
(\mathrm{NS})\end{array}$ & 8 & 4 & 2 & +4 & -3 to +19 \\
\hline Stroke index, $\mathrm{ml} / \mathrm{beat} / \mathrm{m}^{2}$ & 43 & \pm 3 & $\begin{array}{c}-7.4 \pm 1.2 \\
(<0.001)\end{array}$ & None & 13 & 1 & -17 & -24 to \\
\hline IVC-PA mean transit time, sec & 5.0 & \pm 0.5 & $\begin{array}{c}+0.06 \pm 0.15 \\
\text { (NS) }\end{array}$ & 7 & 5 & 2 & +1 & -20 to +18 \\
\hline PA-LA mean transit time, sec & 5.0 & \pm 0.4 & $\begin{array}{c}+0.48 \pm 0.20 \\
(<0.02)\end{array}$ & 12 & 2 & None & +10 & -24 to +44 \\
\hline IVC-PA blood volume, $\mathrm{ml} / \mathrm{m}^{2}$ & 269 & \pm 16 & $\begin{array}{c}-40.7 \pm 9.3 \\
(<0.001)\end{array}$ & 1 & 13 & None & -15 & -38 to +3 \\
\hline Pulmonary blood volume, $\mathrm{ml} / \mathrm{m}^{2}$ & 277 & \pm 22 & $\begin{array}{c}-23.3 \pm 10.3 \\
(<0.05)\end{array}$ & 3 & 11 & None & -8 & -37 to +38 \\
\hline Mean right atrial pressure, $m \boldsymbol{m} \mathbf{H g}$ & 2.9 & \pm 0.4 & $\begin{aligned}- & 3.1 \pm 0.2 \\
& (<0.001)\end{aligned}$ & None & 14 & None & -107 & -300 to -50 \\
\hline $\begin{array}{l}\text { Mean pulmonary arterial pressure, } \\
m m \mathbf{H g}\end{array}$ & 16.4 & \pm 1.3 & $\begin{array}{c}-4.9 \pm 0.6 \\
{[<0.001)}\end{array}$ & None & 14 & None & -30 & -50 to -7 \\
\hline Mean left atrial pressure, $\boldsymbol{m m} \mathbf{H g}$ & 6.4 & \pm 0.8 & $\begin{aligned}- & 4.4 \pm 0.4 \\
& (<0.001)\end{aligned}$ & None & 14 & None & -69 & -125 to -38 \\
\hline $\begin{array}{l}\text { Average intravascular pressure, } \\
\quad m m \boldsymbol{H g}\end{array}$ & 11.4 & \pm 1.0 & $\begin{aligned}- & 4.7 \pm 0.5 \\
& (<0.001)\end{aligned}$ & None & 14 & None & -42 & -60 to -20 \\
\hline $\begin{array}{l}\text { Mean systemic arterial pressure, } \\
m m \mathbf{H g}\end{array}$ & 93.5 & \pm 4.5 & $\begin{array}{c}-2.4 \pm 1.4 \\
(\mathrm{NS})\end{array}$ & 2 & 10 & 2 & -3 & -13 to +5 \\
\hline $\begin{array}{l}\text { Pulmonary vascular resistance, } \\
\qquad m m \mathrm{Hg} / \mathrm{L} / \mathrm{min}\end{array}$ & 1.8 & \pm 0.2 & $\begin{array}{l}+0.2 \pm 0.10 \\
(\mathrm{NS})\end{array}$ & 8 & 6 & None & +11 & -20 to +63 \\
\hline $\begin{array}{l}\text { Total peripheral resistance, } \\
\text { mm } \mathrm{Hg} / \mathrm{L} / \mathrm{min}\end{array}$ & 17.6 & \pm 1.9 & $\begin{array}{l}+3.14 \pm 0.70 \\
(<0.001)\end{array}$ & 13 & 1 & None & +18 & -5 to +40 \\
\hline $\begin{array}{l}\text { Right ventricular stroke work, } \\
g-m / \text { beat } / m^{2}\end{array}$ & 8.6 & \pm 0.9 & $\begin{array}{l}-2.9 \pm 0.1 \\
(<0.02)\end{array}$ & None & 14 & None & -34 & -57 to -11 \\
\hline $\begin{array}{l}\text { Left ventricular stroke work, } \\
\qquad \mathrm{g}-\mathrm{m} / \text { beat } / \mathrm{m}^{2}\end{array}$ & 52.7 & $\pm \mathbf{3 . 0}$ & $\begin{array}{c}-7.4 \pm 1.6 \\
(<0.001)\end{array}$ & None & 13 & 1 & -14 & -32 to \\
\hline
\end{tabular}

* Statistical significance of the difference ( $p$ value) is in parentheses.

The pulmonary arterial and left atrial mean pressures fell in all patients. The average changes were $-30 \%$ (range, -50 to $-7 \%$ ) and $-69 \%$ (range, -125 to $-38 \%$ ), respectively.

There was an increase of the pulmonary vascular resistance in eight patients and a decrease in six. The average change was $+11 \%$, within the -20 to $+63 \%$ range. In nine of the 14 patients, however, variations were not greater than $\pm 10 \%$.

A decline in the pulmonary blood volume was observed in 11 patients, and a rise occurred in thrèe. The changes varied from -37 to $+38 \%$, averaged $-8 \%$, and did not exceed the $\pm 10 \%$ range in nine of the patients studied.

The mean systemic arterial pressure decreased in ten, increased in two, and did not change in a further two patients. The average change was $-3 \%$, and the range was -13 to $+5 \%$.

A fall in the mean right atrial pressure occurred in all patients, with an average decrease of $-107 \%$ (range, -300 to $-50 \%$ ).

The total peripheral resistance increased in 13 patients and decreased in one. The average change was $+18 \%$ (range, -5 to $+40 \%$ ).

The IVC-PA blood volume decreased in 13 patients and increased in one. Changes averaged $-15 \%$ and ranged from -38 to $+3 \%$.

An average fall of $-34 \%$ was observed in the stroke work of the right ventricle, with a range of -57 to $-11 \%$. The left ventricular stroke work decreased in all patients but one. The average change was $-14 \%$, with a range of -32 to $0 \%$. 
DE FREITAS, FARACO, DE AZEVEDO, ZADUCHLIVER, AND LEWIN
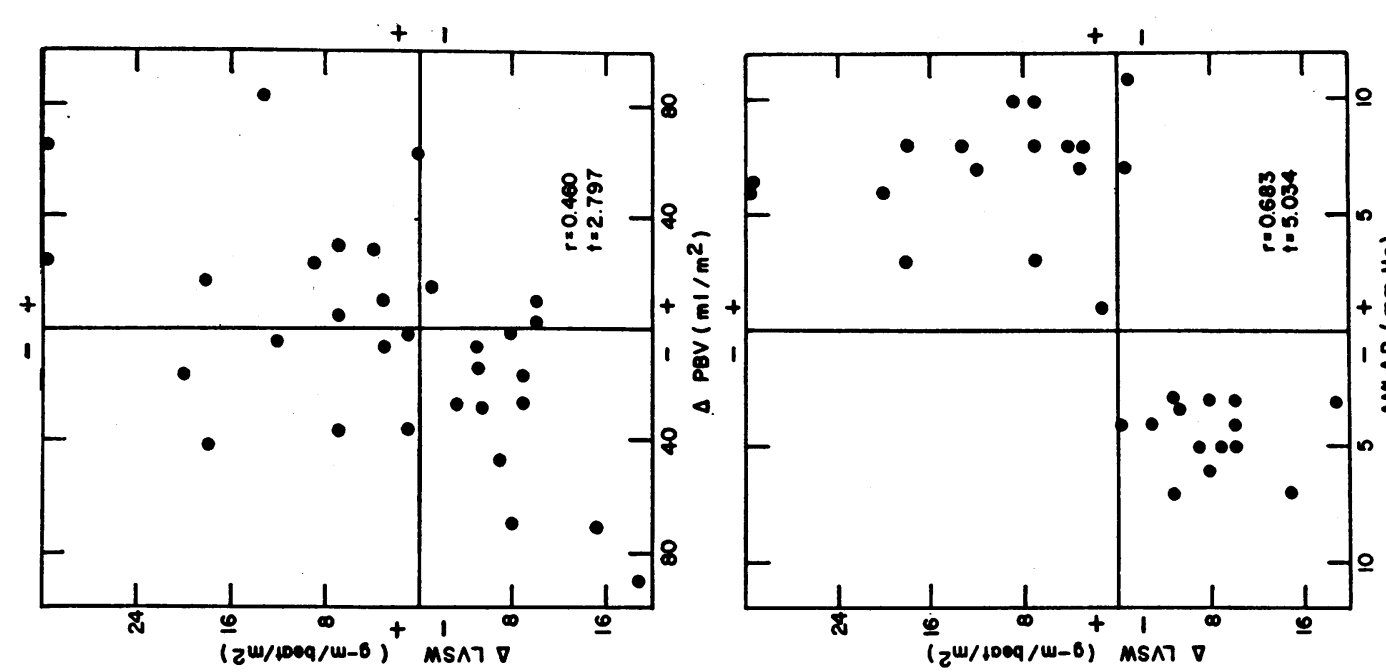

萧

왕

4

嵌

要

I

\&

点总

愡

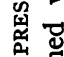

戈

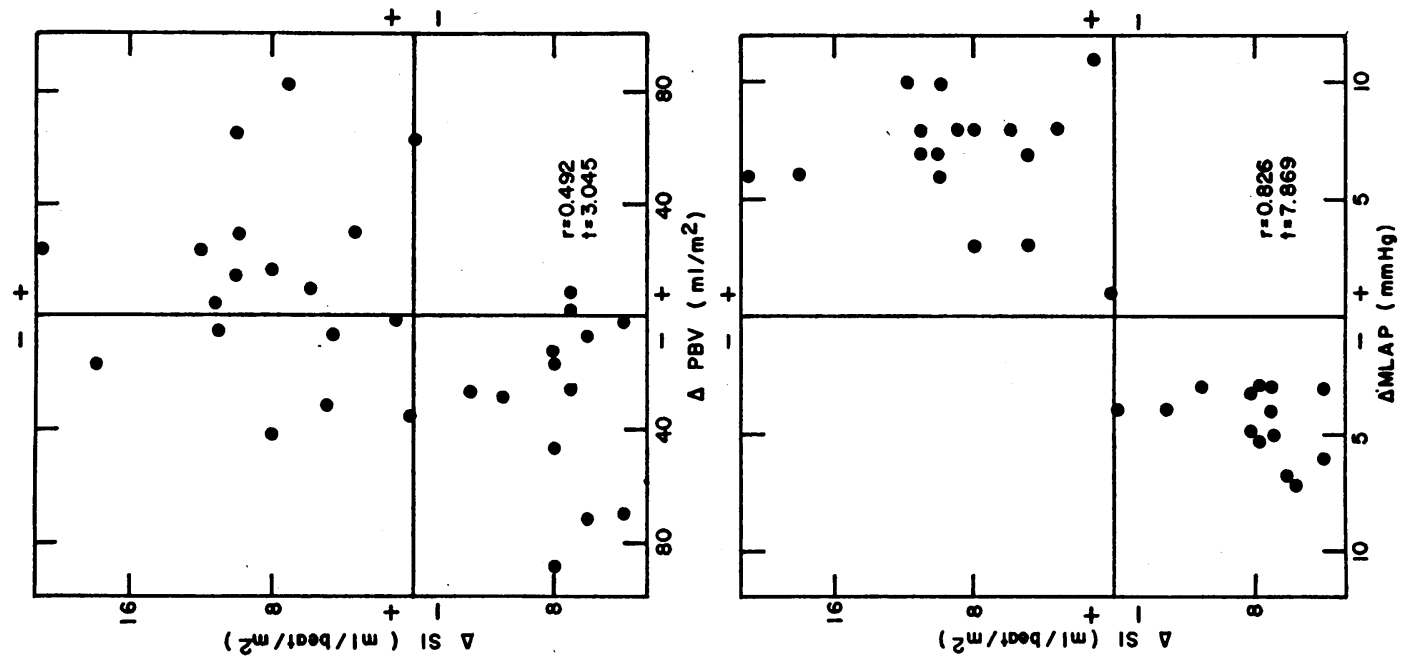

里

密密士

可

$\dot{5}$

觉

$>a$

흥

을

。ํํㄹ

용

西

政

ชิ

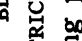

帘.

空要

불

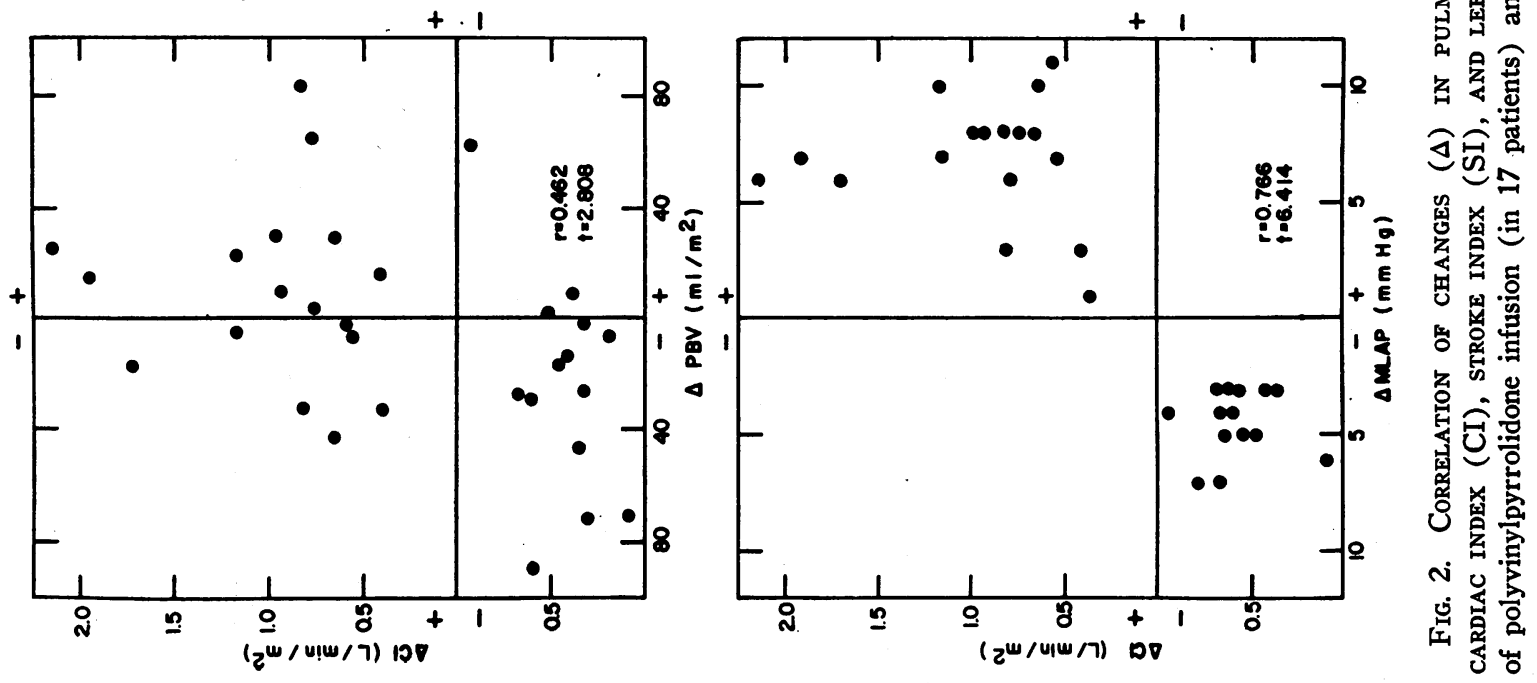


Correlations. The analysis of control data from all patients revealed that the pulmonary blood volume correlated poorly with the cardiac index $(\mathrm{r}=+0.487, t=3.107, \mathrm{p}<0.01)$, stroke index $(\mathrm{r}=+0.464, t=2.917, \mathrm{p}<0.01)$, and mean left atrial pressure $(\mathrm{r}=+0.497, t=3.189, \mathrm{p}<$ 0.01 ) and did not correlate with the mean pulmonary arterial pressure or the pulmonary vascular resistance.

The absolute changes undergone by some hemodynamic variables after the infusion of $1,000 \mathrm{ml}$ of polyvinylpyrrolidone solution or during peripheral venous blood pooling, or both, were examined in each patient for possible correlations.

The correlation coefficients obtained by the comparison of the absolute changes in pulmonary blood volume with the changes in cardiac index, stroke index, and left ventricular stroke work were the following: $\mathrm{r}=+0.462(t=2.808, \mathrm{p}<0.01), \mathrm{r}=$ $+0.492(t=3.045, \mathrm{p}<0.01)$, and $\mathrm{r}=+0.460$ $(t=2.797, \mathrm{p}<0.01)$, respectively (Figure 2 ). A positive relationship was found between the changes in pulmonary blood volume and in mean left atrial pressure $(\mathrm{r}=+0.590, t=3.940, \mathrm{p}<$ $0.001)$. The correlation was poorer when the variations in pulmonary blood volume and in mean pulmonary arterial pressure were compared $(\mathrm{r}=+0.397, t=2.331, \mathrm{p}<0.05)$.

No correlation could be demonstrated between the alterations undergone by the pulmonary vascular resistance and those suffered by the pulmonary blood volume or the average intravascular pressure in the pulmonary circuit.

Better correlation coefficients were found between the absolute changes in mean left atrial pressure and the changes in cardiac index $(r=+0.766$, $t=6.414, \mathrm{p}<0.001)$, stroke index $(\mathrm{r}=+0.826$, $t=7.869, \mathrm{p}<0.001)$, and left ventricular stroke work $(\mathrm{r}=+0.683, t=5.034, \mathrm{p}<0.001)$, as shown in Figure 2.

Correlations of high statistical significance were also demonstrated between the changes in IVC-PA blood volume and the variations occurring in cardiac index $(\mathrm{r}=+0.703, t=5.329, \quad \mathrm{p}<$ $0.001)$, in stroke index $(\mathrm{r}=+0.736, t=5.860$, $\mathrm{p}<0.001)$, and in right ventricular stroke work $(\mathrm{r}=+0.674, \quad t=4.916, \mathrm{p}<0.001)$. Similar results were obtained when the absolute changes of the mean right atrial pressure were compared with those of the cardiac index $(\mathrm{r}=+0.861, t=$
9.117, $\mathrm{p}<0.001)$, stroke index $(\mathrm{r}=+0.730$, $t=5.390, \mathrm{p}<0.001)$, and right ventricular stroke work $(\mathrm{r}=+0.579, t=3.829, \mathrm{p}<0.001)$.

\section{Discussion}

Relationship between pressure and mean blood flow: pulmonary vascular resistance. If other factors that can influence the calculated pulmonary vascular resistance (21) are kept constant, its changes may be accepted as an indication of changes in the caliber of the small pulmonary vessels (including the opening or closure of parallel vascular channels) resulting from variations undergone by transmural pressure or vascular wall tone or both. In the present investigation, significant increases or decreases of the average intravascular pressure were coincident with inconsistent alterations of the pulmonary vascular resistance. If only a mechanical passive effect were involved, the vascular resistance should have varied inversely with the distending pressure (13). Since this did not happen, it can be postulated that the tone of the vessel walls increased after polyvinylpyrrolidone infusion and decreased during peripheral venous blood pooling. For this postulation to remain valid, it has to be accepted that the blood viscosity and the respiratory factors interfering in pulmonary vascular resistance (13, 21) have suffered no important changes throughout the entire period of study, which seems a reasonable assumption.

Relationship between pressure and pulmonary blood volume. Since the alterations demonstrated in the pulmonary vascular pressures were followed in most patients by small changes in pulmonary blood volume, mainly during the infusion of the plasma expander, one is led to the conclusion that the pulmonary vascular bed behaved as a system of low distensibility in the particular circumstances of this study. This was especially true at the higher distending pressures. For this finding to be further illustrated, mean values for cardiac index were plotted against mean values for pulmonary mean transit time, at the various "effective" blood volumes (Figure 3). Since control data for both cardiac index and pulmonary mean transit time were similar before the infusion of polyvinylpyrrolidone (Table I) and peripheral venous blood pooling (Table II), a composite 


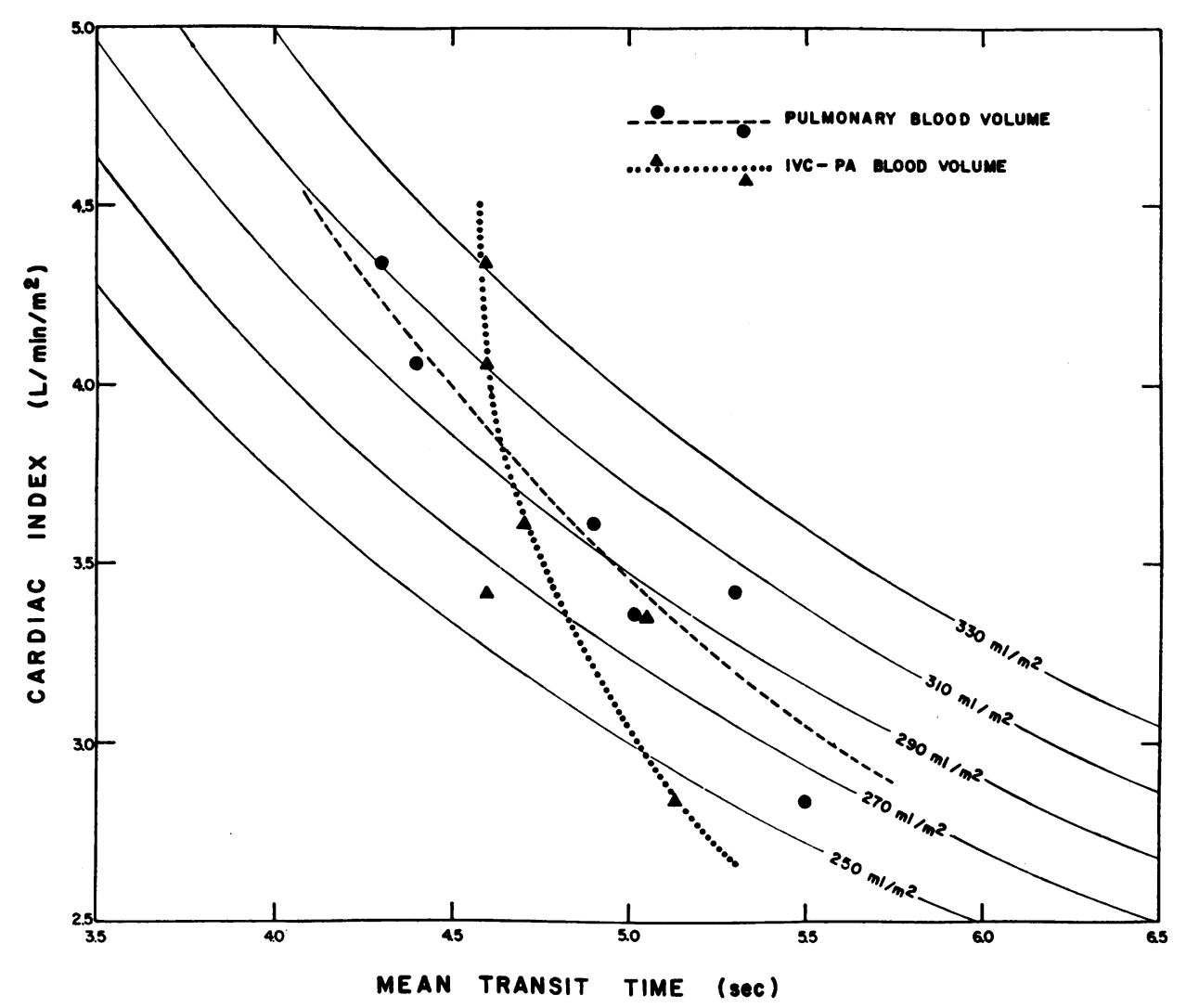

Fig. 3. RELATIONSHIP BETWEen CARDiaC INDEX, MEAN TRANSit TIME, AND BLood volumes IN A) THE PULMONARY CIRCULATION AND B) THE INFERIOR VENA CAVA TO PULMONARY ARTERY (IVC-PA) SEgment. Circles represent mean values obtained in the pulmonary circulation during control periods, polyvinylpyrrolidone infusion, and peripheral venous blood pooling. Triangles represent mean values obtained in the IVC-PA segment during the same periods of study. Dashed line is a composite curve representing the average behavior of the pulmonary blood volume. Dotted line is the same for the IVC-PA blood volume. Solid lines represent the behavior of ideal rigid systems with volumes close to those studied.

curve was drawn, representing the average behavior of the pulmonary blood volume during both procedures. This curve deviated slightly from curves representing different rigid systems ${ }^{5}$ of similar volumes (Figure 3). Doyle, Lee, and Kelley reached the same conclusion by measuring the "central" blood volume in several subjects in whom alterations of the blood flow were induced by a variety of agents and procedures (22).

One of the limitations of the method used to

5 In a rigid system, volume remains constant at any flow rate. Consequently, mean flow and mean transit time vary reciprocally. Rigid systems are represented, therefore, by pure hyperbolic curves (22), which can be easily calculated. determine pulmonary blood volume is its inadequacy for measuring differences in volume between the discrete parts of the pulmonary circulation. Thus, only net effects were observed, and different changes in volume or eventual shifts of blood from one to another of the various pulmonary vascular segments could not be detected. However, and provided that the capillary bed does not have a large compliance $(23,24)$, the results here obtained may suggest that the generally low variations in volume observed after polyvinylpyrrolidone infusion and peripheral venous blood pooling have occurred mainly in the pulmonary venousleft atrial segment. Indirect evidence for this is based on two main findings. The first is the absence of significant modification of the pulmonary 
vascular resistance, which was believed to indicate unimportant alterations in the dimensions of the small pulmonary vessels. The second is the fact that the changes in volume correlated better with the changes in mean left atrial pressure than with the changes in mean pulmonary arterial pressures. These findings are particularly meaningful because it could be demonstrated that the absolute variations in pulmonary arterial pressure have significantly exceeded $(\mathrm{p}<0.001)$ those in left atrial pressure. Although the experimental conditions have been quite different, these results are compatible with observations made on excised rabbit lungs (24).

The position of the catheter for dye injection presented the opportunity to analyze a portion of the systemic venous bed, which included the right atrium and ventricle, with a total volume close to that of the pulmonary vasculature plus left atrium. Since significant alterations in right atrial pressures were paralleled in most instances by important changes in the IVC-PA blood volume, it became evident from the comparison established that the systemic venous segment in question has a higher distensibility than the pulmonary vascular bed. This was also demonstrated by plotting the average values for IVC-PA mean transit time against cardiac index, as done for the pulmonary circulation. Another composite curve representing the IVC-PA blood volume was then constructed. The different behavior of both systems studied is clearly shown in Figure 3.

In the living circulation, the physical properties of a vascular bed depend not only on the structure of the vessel walls but also on their functional behavior under a variety of neural and humoral influences. Consequently, the pressure-volume (distensibility) and pressure-flow (vascular resistance) relationships here described may represent the integrated effect of many determinants. There are several reasons to believe that changes in total effective blood volume activate the autonomic nervous control of the circulation (25), mainly through direct action on the intracardiac and vascular stretch-receptors $(26,27)$. As pointed out by Braunwald, Frahm, and Ross, a rise in total blood volume is usually accompanied by a reflex decrease in the tone of the systemic arteriolar and venous beds (28). As a consequence of the decrease in tone, the capacity of the venous bed increases and the infused fluid tends to pool in this portion of the circulatory system. Any notable increment of the volume of blood in the heart and lungs would then be prevented $(25,28)$. Accordingly, the pulmonary circulation would play a completely passive role in the distribution of circulating blood. However, alterations in pulmonary vascular distensibility may also be an important factor in determining the pulmonary blood volume, as suggested by Feeley, Lee, and Milnor (29). This possibility finds some support in the results of the present study. Since minor and inconsistent variations in pulmonary blood volume and pulmonary vascular resistance have followed important increases or decreases in transmural pressure, a passive behavior of the pulmonary vessels is unlikely, and a stiffening or relaxation, respectively, of the vascular walls can be postulated. Whether these changes in distensibility depend on autonomic nervous control will remain a matter of speculation. Although the existence of pulmonary vasomotor nerves cannot be questioned, their physiological meaning is still a subject of dispute (21). Nevertheless, it is noteworthy that a passive distension of the pulmonary vasculature has been suggested to occur by Frye and Braunwald, who measured the "central" blood volume in patients receiving a transfusion of $1 \frac{1}{2} \mathrm{~L}$ of blood during the action of a ganglionic blocking agent. The same patients had no significant change of the "central" blood volume when the same amount of blood was infused in the absence of ganglionic blockade (25).

Relationship of blood volume and ventricular filling pressure (mean atrial pressure) to cardiac output, stroke volume, and stroke work. A direct correlation between the pulmonary blood volume and the stroke volume (and sometimes the cardiac output) has been reported, both in patients with heart disease and in normal subjects (12, 30-32). Such a relationship has led some authors to ascribe an important role to the pulmonary or central blood volume in determining the stroke volume $(12,30-32)$ and cardiac output $(25,30)$, in agreement with previously reported observations (33-35). These findings either were not confirmed by other workers $(16,36)$ or were not always observed after some circulatory alterations had been induced by various methods and drugs 
$(11,30,32,37,38)$. The most evident explanation for these apparent discrepancies is that the ventricular filling pressure is the only way through which the pulmonary blood volume can influence the stroke volume and work (39). Moreover, the filling pressure depends not only on the volume of blood contained in the venous-atrial compartment in direct communication with each ventricle (39), but mainly on the volume-distensibility characteristics of this compartment. As a matter of fact, we have noted a low correlation between the whole pulmonary blood volume and the cardiac output, stroke volume, left ventricular stroke work, and mean left atrial pressure during the control period. This correlation did not improve when the changes in these variables induced by both polyvinylpyrrolidone infusion and peripheral venous blood pooling were compared. However, when the variations in mean left atrial pressure were correlated with the cardiac output, stroke volume, and left ventricular stroke work, better coefficients, with higher significance, were found (Figure 2). This finding is much more expressive when it is known that the values for cardiac output enter the formulae for the computation of the pulmonary blood volume, stroke volume, and stroke work, whereas the mean left atrial pressure is an independent variable that has only a minor influence in the calculation of the stroke work.

As far as the systemic venous-right atrial segment is concerned, the comparison of the changes in cardiac output, stroke volume, and right ventricular stroke work with those of either the IVCPA blood volume or the mean right atrial pressure has furnished highly significant correlation coefficients that are much alike. This may be attributed to this segment's property of being more distensible than the pulmonary venous-left atrial compartment (21). However, it must be admitted that a closer correlation could have been encountered between the stroke volume or cardiac output and the volume of blood in the lungs if the pulmonary venous-left atrial part of this volume could have been measured separately and used for comparison.

Final cornments. We recognize that the methods used for altering the total effective blood volume could produce other modifications that may have been contributory causes of the hemodynamic changes here reported. For instance, the infusion of the polyvinylpyrrolidone solution induced a small decline in hematocrit that could have been responsible, at least partially, for the increase in cardiac output (40). However, since all patients studied had a normal hemoglobin content before the experiment, the fall observed in hematocrit readings could not correspond to a reduction of hemoglobin below the critical level of $10 \mathrm{~g}$ per 100 $\mathrm{ml}$, which would be necessary before the hemodynamic alterations could be ascribed mainly to anemia (40). During the pooling of blood into the veins of the limbs, no change in hematocrit occurred. Therefore, and disregarding other possible factors, it seems valid to consider the hemodynamic changes induced by both procedures as an expression of the adjustments taking place in the cardiovascular system during variations of the total effective blood volume.

\section{Summary}

Hemodynamic changes induced by alterations in total "effective" blood volume were studied in 26 patients with normal pulmonary circulation. For this purpose, simultaneous right- and leftheart catheterization was carried out in each patient, while blood volume was varied by the rapid injection of a $3.5 \%$ polyvinylpyrrolidone solution, by peripheral venous blood pooling, or by both.

During the infusion of polyvinylpyrrolidone, significant increases were observed in cardiac output, stroke volume, right and left ventricular stroke work, pulmonary arterial and venous (left atrial) pressures, right atrial pressure, and in the blood volume between the inferior vena cava and pulmonary artery, which included a portion of the blood in both venae cavae and their tributaries as well as in right atrium and ventricle. The same variables suffered a significant decline during peripheral venous blood pooling. The increase or decrease of the total effective blood volume elicited small or not significant changes in heart rate and systemic arterial pressure. Total peripheral resistance varied inversely with cardiac output.

The significant changes that were noted in the average intravascular pressure in the pulmonic circuit were not paralleled by important alterations of the pulmonary blood volume, especially during the infusion of the solution containing polyvinylpyrrolidone. Low and inconsistent variations were observed in pulmonary vascular resistance. These 
results suggest that the pulmonary circulation behaved, in the particular circumstances of this study, as a system of low distensibility. At the same time, they are consistent with the view that rapid changes in total volemia are accompanied mainly by variations of the systemic venous blood volume while the pulmonary blood volume is kept within narrow limits.

\section{Acknowledgments}

The authors are indebted to Mr. Plinio Degani and Miss Gessy R. Correa for their technical assistance.

\section{References}

1. Estes, E. H., and R. L. McWorter. Induced variations in pulmonary arterial pressure in man (abstract). Amer. J. Physiol. 1949, 159, 568.

2. Doyle, J. T., J. S. Wilson, E. H. Estes, and J. V. Warren. The effect of intravenous infusions of physiologic saline solution on the pulmonary arterial and pulmonary capillary pressure in man. J. clin. Invest. 1951, 30, 345.

3. Witham, A. C., J. W. Fleming, and W. L. Bloom. The effect of intravenous administration of dextran on cardiac output and other circulatory dynamics. J. clin. Invest. 1951, 30, 897.

4. Fleming, J. W., and W. L. Bloom. Further observations on the hemodynamic effect of plasma volume expansion by dextran. J. clin. Invest. 1957, $36,1233$.

5. Schnabel, T. G., Jr., H. Eliasch, B. Thomasson, and L. Werkö. The effect of experimentally induced hypervolemia in cardiac function in normal subjects and patients with mitral stenosis. J. clin. Invest. 1959, 38, 117.

6. Nixon, P. G. F. Peripheral venous pooling and left atrial pressure pulse in mitral disease. Brit. Heart J. 1960, 22, 522.

7. Weissler, A. M., J. J. Leonard, and J. V. Warren. Effects of posture and atropine on the cardiac output. J. clin. Invest. 1957, 36, 1656.

8. Werkö, L. The effect of experimentally induced hypervolemia on the cardiac function in normal individuals and patients with acquired heart disease in Pulmonary Circulation, W. Adams and I. Keith, Eds. New York, Grune \& Stratton, 1959, p. 263.

9. Marshall, R. J., and J. T. Shepherd. Interpretations of changes in "central" blood volume and slope volume during exercise in man. J. clin. Invest. 1961, 40, 375.

10. McIntosh, H. D., W. L. Gleason, D. E. Miller, and J. B. Bacos. A major pitfall in the interpretation of "central blood volume." Circulat. Res. 1961, 9, 1223.
11. Oakley, C., G. Glick, M. N. Luria, B. F. Schreiner, Jr., and P. N. Yu. Some regulatory mechanisms of the human pulmonary vascular bed. Circulation 1962, 26, 917.

12. Milnor, W. R., A. D. Jose, and C. J. McGaff. Pulmonary vascular volume, resistance, and compliance in man. Circulation 1960, 22, 130.

13. Patel, D. J., A. J. Mallos, and F. M. de Freitas. Importance of transmural pressure and lung volume in evaluating drug effect on pulmonary vascular tone. Circulat. Res. 1961, 9, 1217.

14. Brockenbrough, E. C., and E. Braunwald. A new technic for left ventricular angiocardiography and transeptal left heart catheterization. Amer. J. Cardiol. 1960, 6, 1062.

15. Seldinger, S. I. Catheter replacement of the needle in percutaneous arteriography. Acta radiol. (Stockh.) 1953, 39, 368.

16. De Freitas, F. M., E. Z. Faraco, N. Nedel, D. F. de Azevedo, and J. Zaduchliver. Determination of pulmonary blood volume by single intravenous injection of one indicator in patients with normal and high pulmonary vascular pressures. Circulation 1964, 30, 370.

17. Hamilton, W. F., J. W. Moore, J. M. Kinsman, and R. G. Spurling. Studies on the circulation. IV. Further analysis of the injection method, and of changes in hemodynamics under physiological and pathological conditions. Amer. J. Physiol. 1932, 99, 534.

18. Lenkei, S. C., S. M. Fox III, and T. N. Lynn. Accurate technic for the volumetric calibration of dye-dilution curves (abstract). Circulation 1959, $20,727$.

19. Simon, E. Les substituts du plasma humain. Anesth. Analg. 1958, 15, 680.

20. De Freitas, F. M., E. Z. Faraco, and D. F. de Azevedo. General circulatory alterations induced by intravenous infusion of synthetic bradykinin in man. Circulation 1964, 29, 66.

21. Fishman, A. P. Dynamics of the pulmonary circulation in Handbook of Physiology, W. F. Hamilton and P. Dow, Eds. Washington, American Physiological Society, 1963, section 2, vol. 2, p. 1667.

22. Doyle, J. T., R. A. Lee, and E. B. Kelley. Observations on the elasticity of the pulmonary vasculature in man. Amer. Heart J. 1952, 44, 565.

23. Lewis, B. M., R. E. Forster, and E. L. Beckman. Effect of inflation of a pressure suit on pulmonary diffusing capacity in man. J. appl. Physiol. 1958, $12,57$.

24. Engelberg, J., and A. B. DuBois. Mechanics of pulmonary circulation in isolated rabbit lungs. Amer. J. Physiol. 1959, 196, 401.

25. Frye, R. L., and E. Braunwald. Studies on Starling's law of the heart. I. The circulatory response to acute hypervolemia and its modification by ganglionic blockade. J. clin. Invest. 1960, 39, 1043. 
26. Ross, J., Jr., C. J. Frahm, and E. Braunwald. Influence of carotid baroreceptors and vasoactive drugs on systemic vascular volume and venous distensibility. Circulat. Res. 1961, 9, 75.

27. Ross, J., Jr., C. J. Frahm, and E. Braunwald. The influence of intracardiac baroreceptors on venous return, systemic vascular volume and peripheral resistance. J. clin. Invest. 1961, 40, 563.

28. Braunwald, E., C. J. Frahm, and J. Ross, Jr. Studies on Starling's law of the heart. V. Left ventricular function in man. J. clin. Invest. 1961, 40, 1882.

29. Feeley, J. W., T. D. Lee, and W. R. Milnor. Active and passive components of pulmonary vascular response to vasoactive drugs in the dog. Amer. J. Physiol. 1963, 205, 1193.

30. McGaff, C. J., G. C. Roveti, E. Glassman, and W. R. Milnor. The pulmonary blood volume in rheumatic heart disease and its alteration by isoproterenol. Circulation 1963, 27, 77.

31. Varnauskas, E., S. Å. Forsberg, J. Widimsky, and S. Paulin. Pulmonary blood volume and its relation to pulmonary hemodynamics in cardiac patients. Acta med. scand. 1963, 173, 529.

32. Giuntini, C., M. L. Lewis, A. Sales Luis, and R. M. Harvey. A study of the pulmonary blood volume in man by quantitative radiocardiography. J. clin. Invest. 1963, 42, 1589.

33. Johnson, S. R. The effect of some anaesthetic agents on the circulation in man, with special reference to the significance of pulmonary blood volume for the circulatory regulation. Acta chir. scand. 1951, suppl. 158.

34. Sjostrand, T. Volume and distribution of blood and their significance in regulating the circulation. Physiol. Rev. 1953, 33, 202.

35. Warren, J. V., and A. M. Weissler. Central blood volume as a factor in the regulation of the circulation (abstract). Circulation 1958, 18, 793.

36. Dock, D. S., W. L. Kraus, L. B. McGuire, J. W. Hyland, F. W. Haynes, and L. Dexter. The pulmonary blood volume in man. J. clin. Invest. 1961, 40, 317.

37. Yu, P. N., G. Glick, B. F. Schreiner, Jr., and G. W. Murphy. Effect of acute hypoxia on the pulmonary vascular bed of patients with acquired heart disease. With special reference to the demonstration of active vasomotion. Circulation 1963, 27, 541.

38. Schreiner, B. F., Jr., G. W. Murphy, G. Glick, and P. N. Yu. Effect of exercise on the pulmonary blood volume in patients with acquired heart disease. Circulation 1963, 27, 559.

39. Sarnoff, S. J., and J. H. Mitchell. The control of the function of the heart in Handbook of Physiology, W. F. Hamilton and P. Dow, Eds. Washington, American Physiological Society, 1962, section 2, vol. 1, p. 489.

40. Fowler, N. O. Plasma substitutes in Handbook of Physiology, W. F. Hamilton and P. Dow, Eds. Washington, American Physiological Society, 1962, section 2, vol. 1, p. 63 .

\section{SPECIAL NOTICE TO SUBSCRIBERS}

Post Offices will no longer forward the Journal when you move.

Please notify The Journal of Clinical Investigation, Business Office, 10 Stoughton Street, Boston, Mass. 02118, at once when you have a change of address, and do not omit the Zip Code number. 